\title{
The 2010 international workshop on optical waveguide theory and numerical modelling
}

\author{
Ana Vukovic · Salah S. A. Obayya
}

Published online: 2 August 2011

(C) Springer Science+Business Media, LLC. 2011

The 18th International Workshop on Optical Waveguide Theory and Numerical Modelling (OWTNM) was held at the University of Cambridge, William Gates Building on 9th-10th April 2010. The OWTNM workshop organised one joint session on Quantum Phenomena together with the European Conference on Integrated Optics (ECIO) (7th-9th April, 2010, Cambridge, UK).

The purpose of the OWTNM workshop series is to enhance the dialogue and exchange of ideas between scientists and experts on current topics and problems. Participation in the workshop has continued to grow with a total of 41 oral presentations and 39 poster contributions structured into 7 interactive oral sessions, 5 invited oral contributions and one poster session. The oral sessions reflected current scientific topics namely: planar waveguide devices with application in communication and sensing, quantum phenomena, periodic structures and photonic bandgaps, numerical methods, analytical modelling techniques, plasmonics and metamaterials and their applications.

This Special Issue of Optical and Quantum Electronics devoted to the Cambridge OWTNM meeting is the latest in a long series assigned to the workshops. We are delighted that the Special Issue highlights the contributions in three major areas namely, photonic nanostructures and photonic bandgap structures, coupled resonators and tapered structrures, and plasmonics. It was a great pleasure and honour to act as Guest Editors for this Special Issue. We would like to thank the authors for their excellent contributions and reviewers for their efficient response. Special thanks go to Professor Trevor Benson for his guidance and help throughout.

\footnotetext{
A. Vukovic $(\bowtie)$

Faculty of Engineering, George Green Institute for Electromagnetics Research, University of Nottingham, Nottingham, NG7 2RD, UK

e-mail: ana.vukovic@nottingham.ac.uk

\section{S. S. A. Obayya}

Faculty of Advanced Technology, Integrated Communication Research Centre, University of Glamorgan, Pontypridd, CF37 1DL, UK

e-mail: sobayya@glam.ac.uk
} 
The 2011 OWTNM workshops is planned for Lausanne, Switzerland while OWTNM 2012 will be co-located with ECIO in Sitges, $30 \mathrm{~km}$ south of Barcelona in Spain, in April 2012.

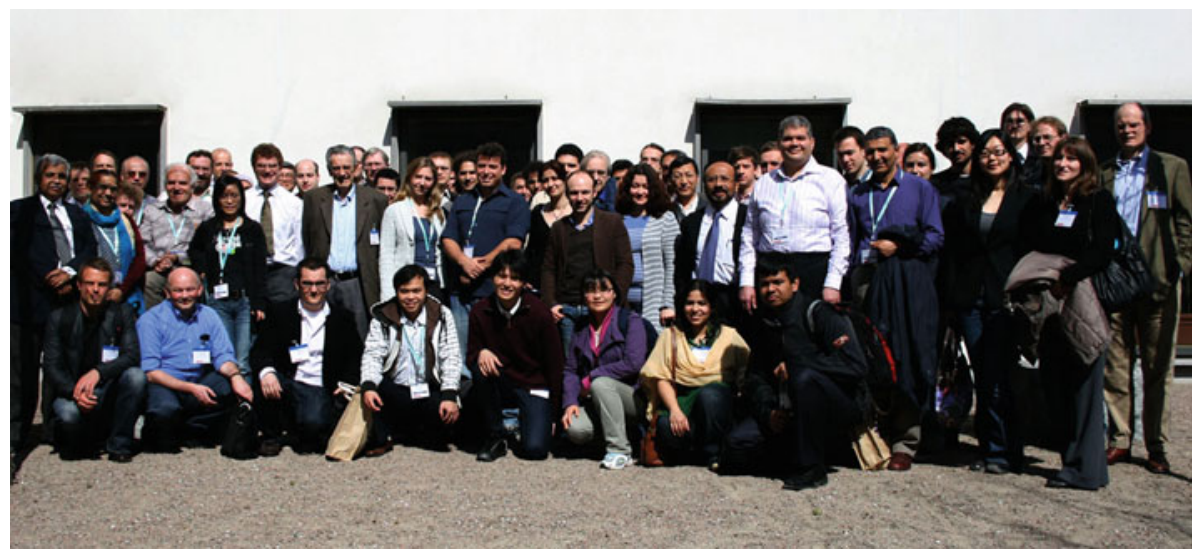

